Euskal ikerketen aldizkaria | Revue d'études basques |

Revista de estudios vascos | Basque studies review

19 | 2016

Numéro XIX

\title{
Oharrak euskal gramatikagintza zaharreko terminologiaz
}

Ricardo Gómez-López

\section{OpenEdition}

\section{Journals}

Édition électronique

URL : https://journals.openedition.org/lapurdum/3389

DOI : 10.4000/lapurdum.3389

ISSN : 1965-0655

Éditeur

IKER

Édition imprimée

Date de publication : 1 janvier 2016

Pagination : 299-307

ISBN : 978-2-95534-134-6

ISSN : $1273-3830$

Référence électronique

Ricardo Gómez-López, «Oharrak euskal gramatikagintza zaharreko terminologiaz», Lapurdum [Linean], 19 | 2016, Sarean emana----an 01 janvier 2021, kontsultatu 03 septembre 2021. URL: http:// journals.openedition.org/lapurdum/3389; DOI: https://doi.org/10.4000/lapurdum.3389 


\section{Oharrak euskal gramatikagintza zaharreko terminologiaz}

Ricardo Gómez-López

UPV/EHU

\section{Sarrera ${ }^{1}$}

Artikulu honetan euskal gramatikagintza zaharra ongi eta zuzen aztertzeko ezinbestekoa iruditzen zaidan gai batez jardungo dut: terminologia. Euskal gramatikagintza zaharraz orain dela hogeita hamar urte baino zerbait gehiago dakigu. Hala ere, nire ustez, bi dira arlo honetan oraindik dauzkagun bi eginkizun behinenak: (a) alde batetik, euskal gramatika-testu zaharren edizio egokiak prestatzea (ik. Gómez 2008b); eta (b) gramatika-testu bakoitzari buruzko azterketa monografikoak egitea.

Bigarren eginkizun horretan, besteak beste, euskal gramatikari zaharren terminologia dugu aztergai. Izan ere, gramatikari zaharren testuak sakonki eta osoki ulertzeko, haietan erabili terminologia ere arretaz aztertu behar da. Horren arrazoia begien bistan dago: terminoen esanahi zehatza jakin gabe, gramatika batean agertzen diren analisiak, deskribapenak, sailkapenak, etab. oker interpretatzeko arrisku handia daukagu. Esate baterako, denok uste (eta nahi) baino maizago, gramatika-testu zaharrak irakurtzen ditugunean, haietan agertzen diren terminoei zuzen-zuzenean —oharkabean izanik ere- gaurko esanahiak ematen dizkiegu, edo esanahi okerrak bederen, testuen irakurketa azalekoegia egiten dugulako.

Lan honen helburua, hortaz, hauxe da: euskal gramatika zaharretan erabilitako termino batzuk azaltzea eta, horren bitartez, hizkuntz terminoen esanahiak ongi eta zehatz-mehatz atzematearen abantailez ohartaraztea.

Horretarako, lehenik eta behin, hizkuntz terminologiak Hizkuntzalaritzaren

1. Artikulu honek hurrengo proiektuen laguntza izan du: "Monumenta Linguae Vasconum (IV): textos arcaicos vascos y euskera antiguo" (Espainiako MINECO, FFI2012-37696) "Historia de la lengua vasca y lingüística histórico-comparada" (HLMV-LHC) (Eusko Jaurlaritza, GIC. IT698-13) eta "Hizkuntzalaritza Teorikoa eta Diakronikoa: Gramatika Unibertsala, Hizkuntza Indoeuroparrak eta Euskara" (HiTeDi) (UPV/EHU, UFI11/14). Nire esker ona adierazi nahi diot Cirilo Garcíari, gramatikari latindarrei buruzko zenbait datu helarazteagatik. 
Historiografiari sortzen dion arazo orokorraz arituko naiz (§ 2); ondoren, euskalari zahar batzuen termino eta termino-bikoteen adibideak ekarriko ditut: Oihenarten verba simplicia / verba composita (\$3.1), coniugatio propria / coniugatio impropria (\$ 3.2) eta auxiliaris (\$ 3.3), eta, azkenik, Larramendiren terminaciones absolutas / terminaciones transitivas edo relativas (§ 4).

\section{Terminologiaren arazo orokorra}

Hizkuntzalaritzaren terminologiaren historiari buruzko ardura ez da oso aspaldikoa. Hura aztertu beharra aldarrikatu zuen Bruneau (1940) bezalako aitzindariren bat alde batera utzirik, hizkuntz terminoak ikertzeko gogoeta metodologikoak 1980ko hamarkadan hasi ziren, Koerner $(1987,1993)$ eta Mugdam (1990) bezalako autoreen eskutik.

Berrikiago, xxi. mendean gaiaren garrantzia berriro nabarmendu bide da eta, horren ondorioz, hizkuntz terminologiari eta haren historiari buruzko biltzarrak antolatu eta monografikoak argitaratu dira, hala nola Colombat \& Savelli (2001) edo Bruley \& Suso (2015). Bereziki aipagarriak iruditzen zaizkit hizkuntz terminologia ikertzeko programa oso bat aurkeztu duten Swiggers-en lanak (2009, 2010, etab.).

Laburki, eta, jakina, gaia agortzeko inolako asmorik gabe, arazo nagusia hauxe da: hizkuntzalaritzaren historian zehar terminologia aldatu egin da. Beraz, kontuan hartu beharko genukeen lehenengo aztergaia termino bakoitzaren kronologia litzateke; hots, terminoaren iturriak arakatu, ala berrikuntza baten aurrean gauden ohartu. Ildo horretan, aintzat har dezagun terminologiaren transferentzia orokorrak izan direla: Berpizkundetik aurrera abiatu zen herri hizkuntzen gramatizazioan erabili den terminologia latinaren gramatikagintzatik mailegatu zen, eta horrek grekoarenari hartu zion; gaurko hizkuntz terminoen kopuru handi bat oraindik iturri horietatik datorkigu (cf. Gómez Asencio 2001).

Bigarren aztergai bat terminoen definizioa dugu. Eta termino bakoitza xeheki ezagutuko badugu, nahitaezkoa da bi mailatan aritzea: alde batetik, terminoaren esanahia terminoa agertzen den testuan bertan interpretatzen ahalegindu behar dugu, gramatikariak eman zion esanahi zehatza lortzeko asmoz; beste alde batetik, termino berbera agertzen den gainerako testuetako agerraldiekin erkatu behar dugu, beste hizkuntzetan, tradizioetan edo garaietan aurki genitzakeen antzekotasunak eta diferentziak aztertzeko.

Eginkizun honetan historiografoaren azken lana, bere idatzien bitartez, iraganeko hizkuntz terminologia gaurko irakurleei azaltzea da. Hizkuntzalaritzaren historiografoak terminologia bien arteko egokitasuna bilatu behar du. Hau da, gramatika-testuen esanahia gramatikari zaharrek pentsatu zuten moduan ulertu behar du eta, ondoren, gaurko irakurleei ulertarazi. Horretarako, historiografoak lehengo hizkuntza gaurkoaren bitartez definitzen eta parafraseatzen ahalegindu behar du, irakurleak ongi jabetu daitezen; baina, jakina, hori guztiori gramatika-testua osoki ulertzea lortu ondoren egin lezake, ez lehenago, terminologia barne.

\section{Oihenart}

Aspaldidanik aitortu dira Arnaud Oihenarten Notitiako (1656 [1638]) gramatikakapituluen balioa eta zorroztasuna, eta haren ekarpen nagusiak behin baino gehiagotan nabarmendu dira (cf., besteak beste, Oihartzabal 1989, 1994; Gómez 1997, 2008; Gómez \& Urgell 2010). Halarik ere, zuberotarraren testuak badu oraindik zer ikertu, eta, hain zuzen ere, hurrengo lerroek Oihenartek erabili zuen terminologian argi pixka bat egitea dute xede. 


\subsection{Verba simplicia / verba composita}

Hona dakardan Oihenarten lehenengo termino-bikotea verba simplicia / verba composita da. Notitiaren bigarren argitaraldian (1656: 62-63), honela hasten da aditzari buruzko lehen atala: ${ }^{2}$

a. "Verborum alia sunt Simplicia, alia Composita: componuntur autem ex particulis præpositiuis aut subiunctiuis, separabilibus aut inseparabilibus. Prcepositiua separabiles sunt affirmatiua bay, \& negatiua es: Inseparabiles verò optatiua ay, id est, vtinam, $\&$ conditionalis $b a$, hoc est, si. Subiunctiuce exdemque inseparabiles sunt la, id est, quòd vel vt, laric h. e. Cum, vel posteaquem, lacoz quia, ean quando, no dum vel donec, s vel es vtrum?"

b. Los verbos son simples y compuestos, y éstos se componen de partículas afijas [sic] o sufijas, separables o inseparables. Las afijas separables son la afirmativa bay y la negativa ez. Las inseparables son la optativa ay, ojalá, y la condicional ba, si. Las sufijas inseparables son la, que [...] y laric, como, después que; lacoz porque; eam, cuando; no, mientras; S o ez, zacaso? (Oihenart 1926: 341)

Jarraian, Oihenartek aditz konposatuen (composita) adibideak ematen ditu: banais (baiezkoa), enais/esnais, ainins 'ainintz', esainins, banais (baldintzazkoa) eta espanais aurrizkidunak; naisela, naiselaric, naiselacoz, naisenean, naiseno eta naisans/naisanes atzizkidunak. Orobat iraganaldiko eta geroaldiko beste adibide batzuk: nainsela, nainselaric eta nasaiteela, nasaiteelaric, hurrenez hurren.

Aipatu ditudan adibideetatik ondoriozta dezakegu Oihenartek composita deitu ziela konplementatzaile bat edota bai, ez atxikiak dituzten adizkiei. Euskal gramatika zaharretan gehiagotan aurkitzen da aditz-joko bakunen eta aditz-joko konposatuen arteko bereizketa. Baina, Larramendiz geroztik (1729), termino horiek batez ere aditz-joko trinkoari (conjugación simple edo sencilla) eta perifrastikoari (compuesta) deitzeko erabiliko dira. Hortaz, termino berberak ditugu, nahiz eta autore guztiak terminoen adierarekin bat etorri ez.

Aditzari gagozkiola, gramatikari latindarrek ere simplicia eta composita terminoak erabili zituzten, baina bigarrenak aditz eratorriak izendatzen zituen, izen eratorriak dauden bezalaxe. Esaterako, hona Priszianok Institutiones grammaticae lanean (v-vI. m.) dakarren sailkapen hirutarra: "Figura quoque accidit verbo, quomodo nomini. alia enim verborum sunt simplicia, ut 'cupio', 'taceo', alia composita, ut 'concupio', 'conticeo', alia decomposita, id est a compositis derivata, ut 'concupisco', 'conticesco'” (VIII, 81; apud Keil 1855: II, 434). Pentsa

2. Oihenarten testuaren aipuak egiteko, 1656ko latinezko jatorrizkoa ez ezik, RIEV aldizkarian argitaratu zen gaztelaniazko itzulpenaz ere baliatuko naiz (Oihenart 1926), irakurleak errazago ulertuko duelakoan. Nolanahi ere den, ohartarazi nahi nuke Gorosterratzuren itzulpenak zenbait akats dituela eta, beraz, Oihenarten testua erabat zuzen ulertzen dugula ziur egongo bagara, nahitaezkoa dela latinezko testura jotzea. Desberdintasun esanguratsurik dagoenean, 1638ko edizioa ere ekarriko dut, horren azpian Orpustanen frantsesezko itzulpen argitaragabea eskainiz (Oihenart 2014). 
dezakegu, beraz, Oihenarten gramatikan aurkitzen dugun erabilera berrikuntza bat izan zela, eta latinaren gramatikako terminoak euskal adizkien egitura jakin baten berri emateko egokitu zituela.

\subsection{Coniugatio propria / coniugatio impropria}

Oihenartek aurkezten digun hurrengo sailkapena aditza jokatzeko bi moldeei dagokie:

a. Duae sunt coniugandi formae. Altera Propria, Altera impropria, quae fit per circumloquutionem. Propria est cum verbum per seipsum inflectitur, absque vllo alterius vocis adminiculo, vt à themate ek'us, id est, vide, fit Decussat video, decussac vides decussa videt, decussagu videmus, decussasue videtis, decussate vident. Necussan videbam \&c." (Oihenart 1656: 63)

b. Existen dos formas de conjugar. Una propia y otra impropia, que se hace por cincumlocución. La propia es el verbo, que se conjuga por sí mismo, sin ayuda de otra palabra; por ejemplo el verbo primitivo ikus, ver, se conjuga, decussat, veo; decussac, ves; decussa, ve; decussagu, vemos; decussasue, veis; decussate, ven. Necussan, yo veía. (Oihenart 1926: 341)

Nire ustez, goiko paragrafoa ez da lehenengo irakurraldian irudi lezakeen bezain ulerterraza. Alde batetik, argi dago Oihenartek propria deitzen duena joko trinkoari dagokiola, eta impropria, berriz, perifrastikoari. Alabaina bi adjektibo horiek interpretazio bat baino gehiago izan dezakete. Izan ere, berriki arte nik neuk uste izan dut propria hitzaren bitartez Oihenartek adierazi nahi zuela euskarak aditz-joko trinkoa berezkoa zuela, hots, lehena, zaharrena; aitzitik, aditz-joko perifrastikoari impropria deitzean, haren aburuz euskaraz perifrasiak ez direla berezkoak, berriagoak direla esaten zigula (Gómez 1997, 2008a; Gómez \& Urgell 2010). Ikuspuntu hori euskalaritzaren historian Larramendiz geroztik nagusitu zen joko perifrastikoaren antzinatasun eta erregulartasunari kontrajartzen zitzaion, Oihenart aditz-perifrasien berritasuna aldarrikatu zutenen aitzindari agertuz (Gómez 2006).

Ordea, gaur egun bestela ulertu behar dugula deritzot: Oihenarten sailkapena aditzaren egiturari legokioke, ez euskararen diakroniari-edo. Interpretazio berri horren gakoak Oihenarten testuak berak ematen dizkigu: joko trinkoa propria da, aditza bera jokatzen delako ("per seipsum inflectitur"), eta joko perifrastikoa impropria da, aditza jokatzeko beste aditz baten laguntza behar duelako ("per circumloquutionem").

Berriro ere, propria eta impropria terminoak adiera horiekin erabiltzea Oihenarten berrikuntza dela dirudi, ez baitira horrela agertzen latindar gramatika zaharretan, ezta Berpizkundekoetan ere, nik dakidala bederen. Jakina, gaur egun bezala, latinaren gramatiketan proprius, - $a$, -um terminoa izen bereziak izendatzeko erabiltzen zen, adibidez; edo grekozko erreduplikazioetan ere propria eta impropria sailkatzen dituzte. Baina, aditzari dagokionez, funtsean proprius, - $a$, -um adjektiboa agertzen zaigu desinentzia bat aditz-joko bati dagokiola adierazteko, hala nola -eo hondarkia bigarren jokoari dagokiola adierazteko, Priszianok egin bezala: "Secunda coniugatio in 'eo' desinit. et ea terminatio propria est secundae coniugationis, exceptis paucis primae coniugationis" (IX, 40; apud Keil 1855: II, 476). 


\subsection{Auxiliaris}

Hona dakardan Oihenarten azken terminoa auxiliaris da, joko perifrastikoaren eraketa azaltzean erabiltzen baitu:

(3) a. "Conjugatio Impropria est cum verbum coniugatur, non per se, sed circumloquutione, per participium suum \& verbum substantiuum nais hoc est sum \& eius auxiliare adi, si verbum sit passiuum vel neutrum, Actiuum vero per verbum possessiuum dut, hoc est, habeo, \& eius auxiliare esac vt, Eziten nais iaceo, Sehazen vel Sehatu nais caedor, Ecusten dut video." (Oihenart 1656: 63)

b. La conjugación impropia es, cuando el verbo no se conjuga por sí, sino por circumlocución, mediante el participio suyo y el verbo substantivo naiz, soy, y su auxiliar adi, si el verbo se hace pasivo o neutro. Mas el activo por el verbo posesivo dut, tengo, y su auxiliar ezac: Ezicen naiz, yazgo: Sehazen o Sehatu nay, estoy despedazado. Ecusten dut, veo. (Oihenart 1926: 341-342)

Bistan denez, auxiliaris terminoaren euskarazko ordaina laguntzaile da. Baina zeren laguntzaile? Oihenartek ematen dion adiera ez dagokio aditz nagusiaren laguntzaileari; alegia, Oihenartentzat laguntzailea ez da aditz oso bat — egungo aditz nagusia— jokatzeko, informazio gramatikal edota funtzionala gehituz zenbait modu eta denbora eratzen laguntzen dion aditz "arina", gaurko adierari legokiokeena. Horren ordez, Oihenartek esaten digu adi (egungo *edin) nais aditzaren laguntzailea dela; halaber, esac (gaurko *ezan) dud aditzaren laguntzailea dela. Bietan eius 'haren' posesiboa da gakoa. Oihenarten laguntzaileek, horrenbestez, ez diote aditz nagusiari laguntzen, baizik eta joko perifrastikoaren modu eta denbora guztiak ezin osa ditzaketen izan eta edun aditzei. Terminoaren forma gaurkoa bera da, baina esanahia zertxobait desberdina.

Eta irudi luke azken honetan ere Oihenarten berrikuntza baten aurrean gaudela. Latindar gramatikariek ez zuten laguntzaile terminoa erabili, ez baitzuten aditz perifrasien behar ez, antza denez, kontzientzia handirik. Terminoa Frantzian xvi. mendean sortu zen eta xviı.ean nagusitu, hizkuntza erromantzeetako aditz-perifrasietan erabili être eta avoir izendatzeko (Chevalier 1999):

(4) a. "Actiui verbi nota est, verbum auxiliarium, i'ay habeo, sine quo in praeteritis coniugari nequit vllum verbum actiuum." (Pillotus 1550: 20v)

b. La caractéristique du verbe actif, c'est d'avoir un "verbum auxiliarium", i'ay sans lequel aucun verbe actif ne peut être conjugué au prétérit. (Chevalier 1999: 27)

Berpizkundeko gramatikariek, hasiera-hasieratik, laguntzaile terminoa gaurko adierarekin erabili zuten. Hau da, être eta avoir aditzak "laguntzaile" izendatzearen arrazoia izan zen gainerako aditzei laguntzen dietela haien jokoa osatzeko, aditz haien modu eta denbora batzuk jokatzeko. Hona hemen bi adibide argigarri:

(5) a. "Pretermittemus autem vtriusque verbi auxiliarij coniugationes quae ideo sic appello, quod in aliis omnibus inflectendis necessario auxilientur." (Pillotus 1550: 21r) 
b. Telles sont les conjugaisons établies par l'un et l'autre auxiliaire que j'appelle ainsi parce qu'on recourt à eux nécessairement pour établir la flexion entière. (Chevalier 1999: 27)

(6) "Nous appellons ordinairement ces deux verbes ja exposez Auxiliaires, d'autant qu'ils aident à tous les autres, qui empruntent de ceux-cy plusieurs temps pour aider à composer les leurs." (Maupas 1632: 195)

\section{Larramendi: terminaciones absolutas / transitivas edo relativas}

Amaitzeko, Larramendik euskal aditza sailkatzeko erabili zuen bereizketa bat azaldu nahi nuke. Lehenik, gramatikari gipuzkoarrak aditz aktibo eta aditz neutroak bereizi zituen, latinaren gramatikagintzatik datorren ohiko sailkapena. Labur esanda, Larramendiren aditz aktiboak NORK aditzak dira eta neutroak, NOR aditzak. Bigarrenik, aditz mota bakoitzaren barruan adizki absolutuak eta adizki iragankor edo erlatiboak daudela diosku:

"Las terminaciones unas son del verbo activo, otras son del neutro. Destas ablaremos en su lugar. Las terminaciones auxiliares del activo unas son absolutas, otras son transitivas, ò relativas: las absolutas se llaman assi, por que no embeben, ni dicen algun respecto, ù orden à ninguna persona del singular, ni plural: las transitivas se llaman assi, por que dicen, y conotan una transicion, ò relacion à alguna de las personas. Las absolutas son de dos generos, y no mas: el primero rige, ò embebe regimen de singular, y el segundo de plural. Las transitivas son de veinte y una especies, por veinte y una relaciones, que puede tener la accion verbal." (Larramendi 1729: 56-57)

Azter dezagun, bada, zein diren aditz aktiboaren adizki absolutuak eta zein iragankorrak. Larramendiren testua arretaz irakurtzen badugu, ondorioa da aktibo absolutuen bi "generoak" det singularraren eta ditut pluralaren paradigmetan aurkitzen ditugula; hots, ZER-NORK adizkiak dei ditzakegunak. Bestalde, aktibo iragankor edo erlatiboak NOR-NORK eta NOR-NORI-NORK paradigmetako adizkiak lirateke. ${ }^{3}$

3. Bidenabar esanda, nahiz eta hain sailkapen argia eman ez, Oihenartek ere Notitiaren lehenengo argitalpenean absolutu/iragankor bereizketa aipatu zuen, eta Larramendiren antzekoa dela dirudi (1638: 70):

(i) a. "quod vnaquæque persona diuiditur in absolutam \& transitiuam: Absoluta nulla re differt à personis verborum Latinorum: Transitiua verò vltra significatum verbi, inuoluit casum obliquum pronominis primæ, secundæ aut tertiæ personæ ad quam sit transitio: sic ab absoluto, Erraten dut, id est, dico, oritur transitiuum, Erraten diat, dico tibi."

b. que chaque personne se divise en absolue ou transitive. L'absolue ne diffère en rien des personnes des verbes latins. Mais la transitive, en plus du sens du verbe, a intégré le cas oblique des pronoms de première, deuxième ou troisième personne: ainsi de l'absolue erraten dut que est "je dis" naît le transitif erraten diat "je te le dis". (Oihenart 2014: 52) 
Geroago, Larramendik dio aditz neutroetan ere joko absolutu (NOR) eta erlatiboak (NORNORI) daudela (1729: 164):

(8) "assi tambien el verbo neutro tiene Conjugacion absoluta, y relativa, admitiendo tantas Conjugaciones, quantas son las combinaciones, y respetos, de que es capaz la accion verbal del Neutro. Es pues una la Conjugacion absoluta, y siete las transitivas, ò relativas de qualquiera verbo neutro."

Larramendiren sailkapenak badu bere munta, gaurko ikuspegitik begiratuta ere. Aktibo absolutuek "no embeben, ni dicen algun respecto, ù orden à ninguna persona del singular, ni plural" dioelarik, irudi luke det eta ditut paragidmetan ez zuela 3. pertsonako objekturik ikusten. Bestela esanda, oso ongi bereizi bide zituela pertsona-komunztadura eta numero-komunztadura, geroagoko hainbat euskal gramatikarik egingo ez dutena.

Euskalaritzaren historian Larramendiren sailkapenak izan zuen segidari dagokionez, aipa dezadan van Eys euskalari holandarrak bere lehenengo gramatikan Larramendiren sailkapena errepikatu zuela (1865: 25-26). Hala ere, bigarren argitaraldirako absolutu/erlatibo bereizketa NOR-NORK vS NOR-NORI-NORK moduan berrinterpretatu zuen (1867: 62); orobat 1879ko gramatika konparatzailean:

(9) "La conjugaison dont les flexions ont le régime direct inhérent, est appelée 'conjugaison absolue'. La conjugaison avec les deux régimes est appelée 'conjugaison relative'.

Il y a par conséquent six conjugaisons avec le régime direct inhérent, puisqu'il y a trois personnes du singulier: je, te, le, \& trois personnes du pluriel: nous, vous, les [...].

Les conjugaisons dites relatives sont au nombre de douze [...]." (van Eys 1879: 132-133)

Atal honen hasieran aipatu dudan aktibo/neutro bereizketa bezala, Priszianoz geroztik latinaren gramatiketan absolutu/iragankor sailkapena ere aurkitzen dugu, honako hau adierazteko: absolutuek ez dute osagarririk eta iragankorrek, aldiz, bai. Hortaz, Larramendirenean bezala, Priszianoren gramatikan sailkapen guztiz sintaktikoa dugu, absolutu eta iragangaitz terminoak esanahikideak izanik. Hona hemen Priszianoren gramatikak ematen dituen aditzaren sailkapenak, Gómez Asenciok (1985: 133) eskaintzen digun taula ezin argigarriagoa baliatuz:

$$
\begin{aligned}
& \text { (ANALOGIA) } \\
& \text { V. activo: significa acción } \\
& -o \rightarrow \text {-or: amo. } \\
& \text { (V. pasivo: significa pasión } \\
& \text {-or } \leftarrow-0) \text { : amor } \\
& V \text {. neutro: -o (y no admite -or): curro }
\end{aligned}
$$

Hau da, aktibo(/pasibo)/neutro sailkapen semantiko-formalaren aldean, iragankor/ iragangaitz edo absolutu sailkapen sintaktikoa dugu, biak ala biak ederki bereiziak. Haatik, 
artikulu honen hasieran adierazi dugunez, hizkuntz terminologia historian zehar aldatu egiten da. Eta bilakaera horretan maiz gertatzen da termino baten esanahi bat baino gehiago garai berean bizi direla.

Hala, bada, hasiera batean Berpizkundeko latindar gramatikek goiko sailkapen semantiko eta sintaktikoak aski ongi bereizi bazituzten ere, nagusiki aditz iragankorren saila aktiboen barruan sartzen zuten eta iragangaitzen saila neutroen barruan. Horren ondorioz, denbora aurrera joan ahala, aktibo termino semantikoa eta iragankor termino sintaktikoa gero eta nahasiago agertuko ziren eta, azken buruan, iragankor terminoak bi adierak hartuko zituen, gaur egun arte aski nahastuta erabili direnak.

\section{Azken hitzak}

Goiko lerroetan euskal gramatika zaharren historia ezagutzeko terminologia aztertzeak duen garrantzia azpimarratu nahi izan dut, horretarako Oihenart eta Larramendi euskal gramatikari zaharren zenbait adibide eskainiz. Adibide horien bitartez erakutsi dut ezinbestekoa dela termino bakoitza arreta handiz definitzea, bai aztergai dugun gramatikatestuaren barruan eta baita bere gramatika-tradizioaren barruan ere. Soilik horrela jokatzeak emango digu bat-bateko eta azaleko interpretazioak saihesteko aukera.

\section{Erreferentziak}

Bruley, Cécile \& Javier Suso (arg.). 2015. La terminología gramatical del español y del francés. La terminologie grammaticale de l'espagnol et du français. Frankfurt: P. Lang.

Bruneau, Charles. 1940. Sur la formation du vocabulaire technique de la grammaire. In Mélanges de philologie et d'histoire littéraire offerts à Edmond Huguet. Paris: H. Champion, 32-51.

Chevalier, Jean-Claude. 1999. La notion d'auxiliaire verbal. Origine et développement. Langages 33(135). 22-32.

Colombat, Bernard \& Marie Savelli (arg.). 2001. Métalangage et terminologie linguistique. Louvain: Peeters.

Gómez, Ricardo. 1997. Euskalaritzaren historia eta historiografia: ikerketa-arloaren egoeraz. ASJU 31(2). 363-391.

Gómez, Ricardo. 2006. "Aditz bakarraren" teoria xIx. mendeko euskal gramatikagintzan. ASJU 40(1/2) 377-407.

Gómez, Ricardo. 2008. Euskal gramatikagintza zaharraren historia laburra: XVII-XVIII. mendeak. In Xabier Artiagoitia \& Joseba A. Lakarra (arg.), Gramatika Jaietan. Patxi Goenagaren omenez, 329-349. Bilbo: UPV/EHU \& Gipuzkoako Foru Aldundia.

Gómez, Ricardo. 2008b. Hacia una edición de textos gramaticales vascos [pdf]. In Monumenta Linguae Vasconum proiektua (2002-2008). Sei urte ikerketan. Vitoria-Gasteiz: UPV/EHU. Interneten eskuragarri: <http://www.ehu.es/monumenta/pdf/mintegia2008/GomezEdicion_textos_gramaticales.pdf>. [Kontsulta: 2015-05-29].

Gómez, Ricardo \& Blanca Urgell. 2010. Descripción y defensa de la lengua vasca durante los siglos XVI y xviI. In Antonio M. González Carrillo (arg.), Post tenebras spero lucem: Los estudios gramaticales en la España medieval y renacentista, 257-320. Varsovia \& Granada: Instituto de Estudios Ibéricos e Iberoamericanos, Universidad de Varsovia \& Universidad de Granada. 
Gómez Asencio, José Jesús. 1985. Subclases de palabras en la tradición española (1771-1847). Salamanca: Universidad de Salamanca.

Gómez Asencio, José Jesús. 2001. Lo latino en las gramáticas del español. In Marina Maquieira Rodríguez, Ma Dolores Martínez Gavilán \& Milka Villayandre Llamazares (arg.), Actas del II Congreso Internacional de la Sociedad Española de Historiografía Lingüística, León, 2-5 de marzo de 1999, 35-54. Madril: Arco/Libros.

Keil, Heinrich (arg.). 1855-1880. Grammatici latini. Leipzig: B. G. Teubner.

Koerner, E. F. Konrad. 1987. Das Problem der Metasprache in der Sprachwissenschaftsgeschichtsschreibung. In Peter Schmitter (arg.), Beiträge zur Historiographie der Linguistik, 63-80. Tübingen: G. Narr.

Koerner, E. F. Konrad. 1995 [1993]. 'Metalanguage' in Linguistic Historiography. In E. F. Konrad Koerner, Professing Linguistic Historiography, 27-46. Amsterdam \& Philadelphia: J. Benjamins.

Larramendi, Manuel. 1729. El impossible vencido. Arte de la lengua bascongada. Salamanca: A. J. Villagordo.

Maupas, Charles. 1632³. Grammaire et syntaxe françoise. Rouen: J. Coilloué.

Mugdan, Joachim. 1990. On the History of Linguistic Terminology. In Hans-Joseph Niederehe \& Konrad Koerner (arg.), History and Historiography of Linguistics, 49-61. Amsterdam \& Philadelphia: J. Benjamins.

Oihenart, Arnaud. 1656 [1638]. Notitia utriusque Vasconiae tum Ibericae tum Aquitanicae. Paris: S. Cramoisy.

Oihenart, Arnaud. 1926. Noticia de las dos Vasconias, la Ibérica y la Aquitana. RIEV 17. 329355. J. Gorosterratzuren gazt. itz., 2. edizioan oinarritua.

Oihenart, Arnaud. 2014. Notitia utriusque Vasconiae... Connaissance des deux Vasconies...J.-B. Orpustanen fr. itz., 1. edizioan oinarritua [eranskin gisa 1656ko edizioko XIV. kapituluko aldaerak dakartza]. Baigorri: ZTK Elkartea. Sareko bertsioa erabili dut: <http://www. tipirena.net/Tipirena_-_Site_officiel_de_Jean-Baptiste_ORPUSTAN/VII._Notitia.html> [Kontsulta: 2015-05-29].

Oyharçabal, Beñat. 1989. Les travaux de grammaire basque avant Larramendi (1729). ASJU 23(1). 59-73.

Oyharçabal, Beñat. 1994. Oihenart, euskal gramatikarien aitzindaria. In Oihenarten Laugarren Mendeurrena. Iker-8, 27-47. Bilbo: Euskaltzaindia.

Pillotus Barrensis, Ioannes. 1972 [1550]. Gallicae linguae institutio. Paris: S. Groulleau. Berrargit. faksim. Genève: Slatkine.

Swiggers, Pierre. 2009. Terminología gramatical y lingüística: elementos de análisis historiográfico y metodológico. Res Diachronicae [pdf] 7. 11-35. Interneten eskuragarri: <http://resdi. net/volumen-vii/>. [Kontsulta: 2015-05-04].

Swiggers, Pierre. 2010. Terminologie, terminographie et métalangage linguistiques: Quelques réflexions et propositions. Revue Roumaine de Linguistique 55(3). 209-222.

van Eys, Willem J. 1865. Essai de grammaire de la langue basque. Amsterdam: C. M. van Gogh.

van Eys, Willem J. 1867. Essai de grammaire de la langue basque. Deuxième édition revue et augmentée. Amsterdam: C. M. van Gogh.

van Eys, Willem J. 1879. Grammaire comparée des dialectes basques. Paris: Maisonneuve. 